\title{
Observing Team Collaboration Personality Traits in Undergraduate Software Development Projects
}

\author{
Shuddha Chowdhury \\ University of Tulsa \\ shc422@utulsa.edu
}

\author{
Charles Walter \\ University of Tulsa \\ charlie-walter@utulsa.edu
}

\author{
Rose F. Gamble \\ University of Tulsa \\ gamble@utulsa.edu
}

\begin{abstract}
Team collaboration is an important aspect of software development. When translated to an undergraduate software engineering class, determining if the team is exhibiting positive collaboration toward successful milestone completion means knowing what actions to reward and when to intervene. Personality traits reflect a person's tendency toward collaborative behavior. However, it remains a challenge to determine if collaborative traits are effective predictors of team project success. In addition, it is unclear if the traits should be measured at the individual or team level. In this paper we examine team member collaborative personality traits and observe their appearance and relationship to grades at each of three product milestones during an undergraduate software engineering course. We use IBM Watson ${ }^{\mathrm{TM}}$ Personality Insights service to process online team conversations. The observed patterns indicate which traits are found in well-performing teams and show how trait manifestation can change during the course of the project.
\end{abstract}

\section{Introduction}

Team-based projects are common in the capstone courses of accredited computer science programs. For many students, this intense level of collaboration among peers has not been previously experienced. Yet it is essential not just for the training in the particular domain, but also for the next career phase of the graduating seniors. The capstone course targeted in this paper is a software engineering course in which teams of undergraduates in their senior year tackle non-trivial projects using modified Agile and Scrum software development processes. The modifications allow for the students to be consistently engaged with the team, promoting asynchronous online tools for collaboration and project management so that the students can focus on their other classes.
In order for early intervention into a team that is struggling to meet deadlines and produce adequate and expected deliverables and work products at the end of each Scrum sprint milestone, an instructor must be able to rapidly gauge the progress of the team. More importantly, once such an assessment targets an underperforming team, the instructor must attempt to pinpoint why and who might be the underlying causes. It is not always the social loafer causing the problem. It may be an overly assertive team member assuming a project lead role, a lone programmer churning out code at a pace too quickly for team review and input, or a perfectionist that refuses to move forward unless everything is exhaustively reviewed. Our hypothesis aligns with research that team dysfunction is not due to one team member, since successful software development teams house all of these, but due to collaboration personality traits within the team. From a pedagogical perspective, intervention can be reduced if team members can recognize how to exhibit their own positive collaborative behaviors as well as learn to be aware of how others' behaviors can have a positive or negative effect on collaborative team efforts.

Whitehead et.al [30] suggests that understanding collaboration for software engineering team development is still a challenge. One of the fundamental obstacles noted is the lack of established metrics to quantitatively measure software team collaboration efforts. From a psychology perspective, personality traits have been linked to improved collaboration. For example, the Big Five model defines 5 categories of personalities, each with subtraits, that have been studied with respect to improving team collaboration ([9], [13], [23], [24], [25]). Additional studies examine these traits in software development teams ([3], [8], [16], [20]) to understand their influence. However, these studies each examine a subset of the traits purported to play a role in collaboration.

The IBM Watson ${ }^{\mathrm{TM}}$ Personality Insights service derives personality traits using a linguistic analyzer from text-based conversations, returning a probability of a person having one or more of the 52 personality 
traits it measures [5]. The availability of this service provides us with a mechanism to evaluate the conversations produced by team members as they interact synchronously and asynchronously on Slack.com, their main team discussion and project management tool. Slack integrates with Trello, Google Drive, and GitLab so that the team activity is readily available through posts.

In this paper, we aim to answer the following hypotheses:

Hypothesis 1: Personality traits identified in the literature as collaborative significantly appear at a rate of $75 \%$ or greater in software development teams.

Hypothesis 2: When a weighted team average is greater than 1.5 for identified personality traits, the overall team grade is greater than $90 \%$.

To answer our hypotheses, we export the posts from the discussion-based channels used by 15 teams comprising a total of 69 students across 3 semesters of the spring software engineering capstone course for computer science majors. We target 26 of the 52 personality traits assessed by the IBM Watson ${ }^{\mathrm{TM}}$ Personality Insights service. These 26 traits have been predetermined by the literature presented in Section 2 to be related to collaboration. We examine the patterns of collaborative traits found in their union and intersection across the team members in the 3 consecutive Scrum sprints that comprise the semester's software product development milestones. We observe these patterns and their relationship to team grades as the main performance metric for students. In addition, we observe the changes in trait emergence throughout the semester as students progress through the sprints. The interpretations of the observed patterns are presented. The results point to other studies that can be conducted in team makeup, especially when combined with more detailed performance metrics and the assessment of engagement with the other collaborative tools.

\section{Background}

Stevens [28] researched the effects of roles and personality characteristics on software development team effectiveness and identified several key characteristics. His research focused on improving the effectiveness of software development teams by forming teams who can work effectively together. He notes that imagination, intellect, curiosity, excitement, cheerfulness, gregariousness, and sociability are some of the most important characteristics in software development team effectiveness and these traits can help with team collaboration.
Li et al. [18] examined the distinguished attributes of great software engineering. They uncovered 53 attributes of great engineers. They emphasized that effective developers are humble or modest about their intelligence, they are curious, imaginative, intelligent, and honest. The authors believe that the above traits have a big impact on team performance and collaboration.

Capretz and Ahmed [7] mapped soft skills and psychological traits to the main stages of the software life cycle. Using the Myers-Briggs Type Indicator (MBTI) personality model, they analyzed job descriptions for software engineers in newspapers, magazines, and posted on monster.com to determine the preferred skills and related them to skill requirements. They mapped the skills rated as desirable and highly desirable to MBTI dimensions. They found that software designers need to cooperate closely with management, engineers, and other designers to evaluate and iterate on ideas and designs. They also need to have strong analytical and problem-solving skills and they need to be innovative, open and adaptable to changes.

McCuller [20] relays his observations of software development teams from his years working at tech companies. He links adventurousness to productive software engineers as it relates to bringing new ideas to the project, experimenting with new tools and techniques, and collaborating with team members. Though seemingly the opposite of adventurousness, cautiousness can also foster collaboration, because people with this personality would consider software reliability, security, and long-term maintenance in more detail early in the product implementation.

From their literature review of team structure and leadership, Hackman and Wageman, [13] found that collaborative activities in which team members work to achieve a common purpose may also require authority challenging team members, as authority challenging team members are likely to prevent the team from making an early mistake made by an authority.

Baumgart et al. [3] looked at what personality traits were vital for the software engineering process. They conducted interviews of eleven team members and found altruism is the most important attribute for successful Agile development. Additionally, they found that self-discipline and dutifulness were also important for collaboration and success in software development. These traits were most often associated with a successful product outcome according to the interviewed developers.

Lindsjørn et al. [19] found that self-discipline, achievement striving, and sympathy were all beneficial for team collaboration in Agile software development. They conducted a survey of 71 software teams, looking 
only at the effect of teamwork quality on team performance. They found that mutual sympathy between team members leads to better team cohesion. Chow and Cao [8] conducted a survey of 109 Agile software developers from 25 countries. They identified four personality attributes that contributed to collaboration: altruism, self-discipline, achievement striving, and dutifulness.

Ramesh, et al. [25] couple cooperation with trust as being necessary for distributed and Agile software development teams. When team members are collocated, there is improved cohesion and team members collaborate more often than when they are at different sites. Cooperation results in team members not only exchanging product knowledge, but also knowledge about their business values and environment. For distributed teams, the authors maintain product repositories to foster cooperative attitudes. But this must be coupled with trust for the knowledge exchange to be accepted by distributed team members.

Emotional range also factors into the collaborative effort experienced by a software development team. Graziotin et al. [11] surveyed 189 participants and identified 49 consequences of unhappiness during software development. They suggest that stress, anxiety or worry, burnout, and depression all have adverse effects on software development teams, negatively impacting collaboration.

Murgia et al. [22] carried out an exploratory study of software developer's emotions using issue comments during software maintenance and evaluation. In their study they found that cheerfulness, excitement, and love (presence of gratitude) affected collaboration positively and the use of these traits improves the software development process and collaboration.

Layman et al. [17] found that awareness of different types of learning helped to create a better learning environment. They also found that students who were well organized, structured, and tidy performed better and showed improved team performance. Based on their study their tried to make their course as orderly and concise possible.

Dunlap [10] carefully examined the role of selfefficacy in undergraduate computer science students completing a 16-week capstone course in software engineering. She noted that problem-based learning helps students acquire the knowledge and skills required in the workplace. She found that the acquisition of knowledge and skills makes it possible for performance to occur, but without self-efficacy performance may not even be attempted. With specific instruction strategies, she found that self-efficacy played a role in collaboration. Those with self-efficacy are confident about their skills and they can contribute significantly to their projects.
Cao and Park [6] studied the effect of several positive and negative emotions in agile software development teams they pointed out that the emotional experiences of the team members may significantly influence their behaviors. Their study examined the role of emotion in agile software development using a multisite case study of two agile project teams. They developed a framework that explains how the project and individual goals trigger emotions and how the emotions influence behaviors and project outcomes. They found out that cheerfulness and excitement have a positive impact on agile software development team collaboration.

Balijepally et al. [1] assessed the personality profiles of software developers in agile development teams based on extensive literature review of personality psychology and group behavior. They compared both Big Five and MBTI personality factors and identified modesty, excitement, outgoingness, orderliness, and gregariousness as being common in agile development teams.

Judge et al. [15] mentioned that positive selfconcept or core self-evaluation is a very important personality trait for predicting job performance. A positive self-concept consists of four specific traits: self-esteem, self-efficacy, locus of control, and emotional stability. They analyzed the data from 12 samples and found that a positive self-concept is directly linked to job performance.

Beranek et al. [4] examined the team structures and many other soft factors for building and leading successful software engineering teams. They note that personality and skill of individual team members plays a big role in building a successful software engineering team. They found that assertiveness, decision making, observation skills, and motivation skills are some of the most important factors found in successful software engineering teams. They describe how improving student's soft skills along with their technical skills will help to create successful software development teams.

Seaman [27] made qualitative research on the human behavioral aspects of software engineering. By observing and interviewing his participants, he found that self-consciousness made the participants nervous and affected their behavior negatively in software development.

Rasmusson [26] noted that sincerity is one of the most important traits in agile software development teams and that a sincere team member manages his content in a simple, comprehensive, and realistic approach so that his team members and customer can understand the content easily. He also pointed out that sincere team members can deliver great software to their customer on time. Sincere team members also try 
to enhance their skills for team improvement and team success.

Guzman and Bruegge [12] pointed out that emotion plays a very important role in team member collaboration in software engineering projects. The authors argued that in large and distributed teams, team members can lose awareness of their projects emotional state. The authors proposed a technique to improve emotional awareness in software development teams with the help of quantitative emotion summaries. They extract summaries of the emotions expressed in collaboration artifacts by combining probabilistic topic modeling with lexical sentiment analysis techniques. They found that emotion summaries have a good correlation with project emotional state.

\section{Class Organization and Expectations}

The software engineering class serves as a capstone, team project development class for computer science, information technology, and game development undergraduate majors in their senior year. The teams are chosen by the instructor based on students self-reporting their ranked project preferences, team members they prefer and do not prefer working with, if the team configuration is more important than the project, and their evaluation of their skillset as it relates to the project needs. All variables are considered. If a team member cannot achieve a first or second project choice due to the other variables, they are individually consulted before team assignment. The teams are self-organizing as no roles are pre-assigned.

The collaborative tools that are used in the class include Slack, Google Drive, Lucidchart, Trello, and GitLab. To understand collaboration initially, we focus on the team use of Slack as the primary online discussion forum for the team projects. Teams are penalized if they use primarily private messaging (percentages are reported by Slack weekly) or other means of communication, which is difficult to police, but often becomes evident inadvertently. Part of modifying the development process for a class setting is the change to the sprint daily meeting requirement. Each student is required to have 2 formal check-ins per week (Monday and Thursday) on the Slack.com team account to express (a) what was accomplished since the last check-in or the start of the Sprint, (b) what will be done before the next check-in or end of the Sprint, and (c) general discussion of the project, how another team member will be aided, or any impediments discovered and their mitigation. This modification retains the spirit of the sprint daily check-in, providing flexibility for the students to address requirements in other classes.
Each modified sprint lasts for approximately four weeks and requires a deliverable portion of the final product to be completed by the end of the sprint. The focus of the deliverable may be dictated by the sprint. The sprints target different work products that combine product deliverables with the learning objectives of the course. For example, sprint 1 generally focuses on interface and database design and delivery. This allows the teams to develop an understanding of user stories and the use of backlogs and other project management tools, such as the Git feature branch workflow. In sprint 1, the team grade revolves around the quality, creativity, and functional depth of the deliverable, the generation and maintaining of the backlog, and specific documentation requirements for vision and feasibility.

The deliverable for sprint 2 focuses on a passthrough of all of the highly relevant functionality of the application. Other work products that support the creation of the deliverable are modeling and analysis, code reviews, and testing. At this point in the class, the teams become comfortable with the breadth of collaborative tool used, instructor and customer expectations, and awareness of team member capabilities, work habits, and work ethics. For Sprint 2, the team is primarily graded on the deliverable (quality, functional depth, and creativity), overcoming technical issues, and documented models.

The sprint 3 deliverable is complete enough for beta testing. Thus, the teams work on quality assurance, along with packaging and transitioning the product to the customer. Work products include a user guide, bug disclosure, troubleshooting, and corrections to prior work products from sprints 1 and 2. The Sprint 3 grade includes the assessment of the product as a whole, the team usage of the time to get a prototype product that is useful to their customer, and product evaluations by peers, external reviewers, and the customer.

Team effort between sprints and at the end of the semester includes time for presentation, customer meetings, Sprint review, and product evaluation.

\section{Using IBM Watson ${ }^{\mathrm{TM}}$ Personality Insights Service}

Slack allows posts from all public channels to be exported into a JSON file. We performed the export for each team and segregated the posts per user per sprint. Submitting the post files to the IBM Watson ${ }^{\mathrm{TM}}$ Personality Insights service yielded a personality score (probability of existence) for the 52 total personality attributes. Based on the literature review presented in Section 2, we filtered out the 26 targeted traits shown across the top of the tables below. Many, but not all, of 
these are included in the Big Five Model ([9], [14], [23]).

Emotionality means students are aware of their feelings and how to express them. Imagination refers to the students view of the world. Low imagination implies students view the world as plain and ordinary. Intellect refers to how open to and intrigued by new ideas the students are. Orderliness means they feel a strong need for structure in their life. Self-efficacy means they feel they have the ability to succeed in the tasks they set out to do.

Cheerfulness means the student is overall cheerful. Outgoing means they make friends easily and feel comfortable around other people. Gregariousness means they enjoy being in the company of others. The students prone to worry tend to worry about things that might happen. The students with a high challenge score have an urge to achieve, to succeed, and to take on challenges. Curiosity means the student has a desire to discover, find out, and grow. Students with stability remain emotionally stable.

Self-enhancement students seek personal success for themselves. Adventurous students are eager to experience new things. Authority Challenging students prefer to challenge authority, such as the instructor. Achievement-Striving students set high goals for themselves and work to achieve them. Cautiousness means the student carefully thinks through decisions before making them. Dutifulness means students take rules and obligations seriously.

Self-discipline means the student is persistent and will stick with tough tasks. Activity Level means the student enjoys a fast-paced, busy schedule with many tasks. Altruistic students feel fulfilled when helping others. Cooperative students are accommodating and easy to please. They try to avoid confrontation. Sympathetic students are empathetic and are more compassionate toward others. Students with high Trust believe the best in others and trust people easily. Students that are Susceptible to Stress are easily overwhelmed in stressful situations. Openness to change implies the student is willing to support a needed change.

\section{Results and Discussion}

We assume that an individual has the personality trait if the trait's probability of existence is above 0.75 , as this shows the trait in question was present in a majority of their Slack posts. Because of the amount of work products and graded points per sprint, we denote which teams received a grade greater than a $90 \%$ for each sprint, which is an above average grade.
In this section, we discuss the traits that had an effect on team collaboration across three sprints. We use grade as our performance metric for this study. We chose the team grade because it is directly related to the students' abilities to collaborate and the success of their project. The team grade is made up of the deliverable grade and documentation grade, as these parts of the project should be worked on by all team members.

To prevent the risk of large teams with a small number of team members having a trait, we weight each team score based on the number of users with the value over 0.75 . We consider a team as a whole to have the trait if their overall weighted score is above 1.5, as this is equivalent to approximately half a normal sized team (with 4 team members) having the trait.

Table 1 shows the results from sprint 1 . Interestingly, all teams had challenge and curiosity. Additionally, most teams had a high activity level. We can see that teams with students who had the Orderliness and Stability traits all had high grades. Additionally, with the exception of teams 8, 9, and 10, those that displayed an openness to change also had high grades. Similarly, Sympathy was shared by all but two of the teams with high grades, as was Susceptible to Stress.

However, for sprint 1 , the teams that lacked specific traits had higher grades. The 5 teams that had their grade above 90 had no team members with the traits Authority Challenging, Achievement Striving, Cautiousness, Dutifulness, Cooperation, and Trust, and only a small number of students with the Intellect trait.

It is reasonable to expect teams that are less cautious to perform better in the first sprint, as those teams are more willing to take a risk and try something that may not work for their project. It is also reasonable to expect teams with low authority challenging traits to do better, as they are more likely to conform to the instructor's requirements and, thus, achieve a higher grade. Adventurousness is also rare in teams that had students with high grades. This may be due to adventurous teams going outside of the class requirements in hopes of completing a more complex deliverable but failing to complete the assigned work products. Oddly, teams that had low cooperation did better, though this is not always the case (as seen by teams 3, 8, and 9). This result could be related to the lack of trust shown in successful teams, as those teams that do not cooperate well and do not trust each other are more likely to check work that is assigned to other team members and ensure it meets the requirements of the course.

For sprint 1 where teams may have to make drastic changes to their project after a short time working on it, an openness to change would be a useful trait to 
have. Stability is also useful in a similar way, as students who are able to remain stable to any changes that occur are more likely to be able to complete their project. Having sympathy for the struggles of other team members is vital for the first sprint, as sympathetic team members are less likely to write off a teammate for a mistake. Finally, having even one person on the team who is orderly makes it far more likely that portions of the project that will be graded will not be missed, allowing teams to more completely complete the project itself.

Table 1. Sprint 1 Personality Assessment

\begin{tabular}{|c|c|c|c|c|c|c|c|c|c|c|c|c|c|c|c|c|c|c|c|c|c|c|c|c|c|c|c|c|}
\hline 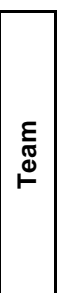 & 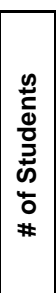 & 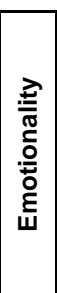 & 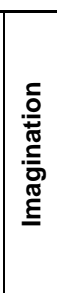 & 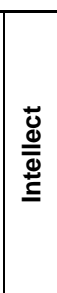 & 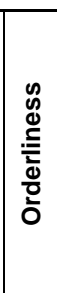 & 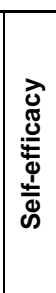 & 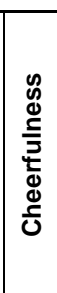 & 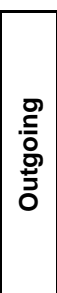 & 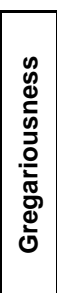 & 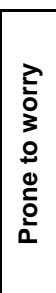 & 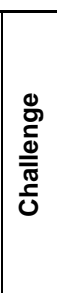 & 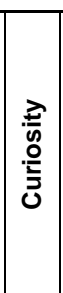 & 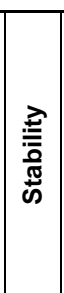 & 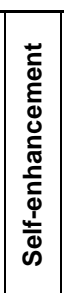 & 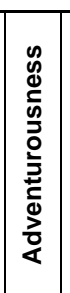 & 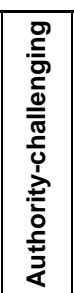 & 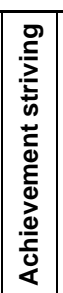 & 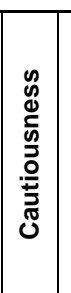 & 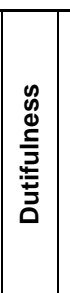 & 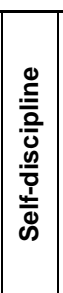 & 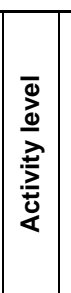 & 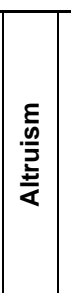 & 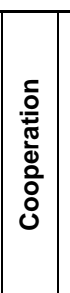 & 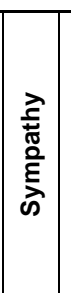 & $\stackrel{\overrightarrow{\underline{n}}}{\overrightarrow{\underline{w}}}$ & 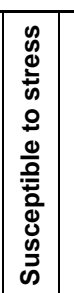 & 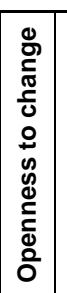 & 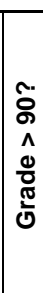 \\
\hline 1 & 4 & 0 & 0 & 3.5 & 0 & 0 & 0 & 0 & 0 & 0 & 1.8 & \begin{tabular}{|l|}
0.8 \\
\end{tabular} & 0 & 0 & 0 & 2.51 & \begin{tabular}{|l|}
0.9 \\
\end{tabular} & \begin{tabular}{|l|}
4.6 \\
\end{tabular} & \begin{tabular}{|l|l}
0.8 \\
\end{tabular} & 0 & 4.9 & 0 & 1.6 & 0 & \begin{tabular}{|l|}
1.9 \\
\end{tabular} & \begin{tabular}{|l|l|}
0.4 \\
\end{tabular} & 0 & $N$ \\
\hline 2 & 5 & 0 & 0 & 1.8 & 0 & 0.4 & 0 & 0 & 0 & 0 & 2.9 & 1.4 & 0 & 0 & 0 & 0.78 & 0 & 2.8 & \begin{tabular}{|l|l}
0.7 \\
\end{tabular} & 0 & 3.6 & 0 & 0 & 0 & \begin{tabular}{|l|}
0.7 \\
\end{tabular} & 0 & 0 & $\mathrm{~N}$ \\
\hline 3 & 4 & 0 & 0 & 1.6 & 0 & 0.6 & 0 & 0 & 0 & 0 & 3.4 & 1.5 & 0 & 0 & 0 & \begin{tabular}{|l}
0.58 \\
\end{tabular} & 0 & \begin{tabular}{|l|}
2.2 \\
\end{tabular} & \begin{tabular}{|l|l}
0.6 \\
\end{tabular} & 0 & 3.4 & 0 & 0 & 0 & \begin{tabular}{|l|}
0.7 \\
\end{tabular} & 0 & 0 & $N$ \\
\hline 4 & 4 & 0 & 0 & 3.5 & 0 & 0 & 0 & 0 & 0 & 0 & 2.4 & 0.7 & 0 & 0 & \begin{tabular}{|l}
1.3 \\
\end{tabular} & 2.63 & \begin{tabular}{|l|}
1.4 \\
\end{tabular} & 3.6 & \begin{tabular}{|l|l}
1.6 \\
\end{tabular} & 0 & 2.5 & 0 & 2.5 & 0 & \begin{tabular}{|l|}
2.4 \\
\end{tabular} & 0.6 & 0 & $\mathrm{~N}$ \\
\hline 5 & 4 & 0 & 0 & 3.7 & 0 & 0 & 0 & 0 & 0 & 0 & 2.5 & 2.6 & 0 & 0 & \begin{tabular}{|l|}
1.4 \\
\end{tabular} & \begin{tabular}{|l}
2.58 \\
\end{tabular} & 0 & \begin{tabular}{|l|}
3.6 \\
\end{tabular} & \begin{tabular}{|l|}
0 \\
\end{tabular} & 0 & 2.4 & 0 & \begin{tabular}{|l|}
0.7 \\
\end{tabular} & 0 & \begin{tabular}{|l|}
3.3 \\
\end{tabular} & 0 & 0 & $\mathrm{~N}$ \\
\hline 6 & 4 & 0 & 0 & 3.7 & 0 & 0 & 0 & 0 & 0 & 0 & 2.3 & \begin{tabular}{|l}
3.4 \\
\end{tabular} & 0 & 0 & 0.6 & \begin{tabular}{|l}
1.53 \\
\end{tabular} & \begin{tabular}{|l|}
0.7 \\
\end{tabular} & \begin{tabular}{|l|}
2.6 \\
\end{tabular} & 2.3 & 0 & 1.5 & 0 & 2.4 & 0 & \begin{tabular}{|l|}
0.7 \\
\end{tabular} & 0.7 & 0 & $\mathrm{~N}$ \\
\hline 7 & 3 & 0 & 0 & 2.7 & 0 & 0.7 & 0 & 0 & 0 & 0 & 2.8 & 2.8 & 0 & 0 & \begin{tabular}{|l|}
1.6 \\
\end{tabular} & \begin{tabular}{|l|}
0.7 \\
\end{tabular} & 2.7 & \begin{tabular}{|l|}
2.8 \\
\end{tabular} & \begin{tabular}{|l|}
0.7 \\
\end{tabular} & \begin{tabular}{|l|l|} 
\\
\end{tabular} & 2.9 & 0 & \begin{tabular}{|l|}
0.6 \\
\end{tabular} & 0 & \begin{tabular}{|l|}
0 \\
\end{tabular} & 0 & 0 & $N$ \\
\hline 8 & 4 & 0 & 0 & 1.5 & 0 & 1.3 & 0 & 0 & 0 & 0 & 2.7 & 1.5 & 0 & 0.6 & \begin{tabular}{|l}
0.8 \\
\end{tabular} & 0.63 & 0.6 & 0 & & 0 & \begin{tabular}{|l}
3.8 \\
\end{tabular} & 0 & 0 & 0 & \begin{tabular}{|l|l}
1.6 \\
\end{tabular} & 0 & 0.6 & $\mathbf{N}$ \\
\hline 9 & 4 & 0 & 0 & 2.4 & 0 & 3.3 & 0 & 0 & 0 & 0.5 & 3.7 & 3.5 & 0 & \begin{tabular}{|l|}
1.4 \\
\end{tabular} & \begin{tabular}{|l|}
1.4 \\
\end{tabular} & \begin{tabular}{|l|l|}
1.43 \\
\end{tabular} & \begin{tabular}{|l|}
0.6 \\
\end{tabular} & \begin{tabular}{|l|l|}
1.4 \\
\end{tabular} & 0.6 & 0 & 3.6 & 0 & 0 & 0 & \begin{tabular}{|l|l|}
1.6 \\
\end{tabular} & 0 & \begin{tabular}{|l|}
1.5 \\
\end{tabular} & $N$ \\
\hline 10 & 4 & 0 & 0 & 3.7 & 0 & 0 & 0 & 0 & 0 & 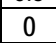 & \begin{tabular}{|l|l} 
\\
\end{tabular} & 2.3 & 0 & 0 & 3.6 & \begin{tabular}{|l|}
3.7 \\
\end{tabular} & \begin{tabular}{|l|}
0.7 \\
\end{tabular} & 3.5 & \begin{tabular}{|l|l}
1.4 \\
\end{tabular} & 0 & 3.8 & 0 & 2.3 & 0 & \begin{tabular}{|l|l}
3.5 \\
\end{tabular} & 0 & 1.5 & \\
\hline 11 & 4 & 0 & 0.6 & 0 & 0.6 & 0 & 0 & 0 & 0 & 0 & 2.4 & \begin{tabular}{|l|}
3.8 \\
\end{tabular} & \begin{tabular}{|l}
1.3 \\
\end{tabular} & 0 & 0 & 0 & 0 & \begin{tabular}{|l|}
0 \\
\end{tabular} & 0 & 0 & 1.4 & 0 & 0 & 0 & 0 & 2.5 & \begin{tabular}{|l|} 
\\
\end{tabular} & $Y$ \\
\hline 12 & 6 & 0 & 0 & 0 & 0.7 & 0 & 0 & 0 & 0 & 0 & 3.1 & 5.8 & \begin{tabular}{|l|}
1.4 \\
\end{tabular} & 0 & 0 & 0 & 0 & 0 & 0 & 0 & 0 & 0 & 0 & 0 & 0 & \begin{tabular}{|l|}
4.1 \\
\end{tabular} & 2.2 & $\bar{Y}$ \\
\hline 13 & 8 & 0 & 2.2 & 1.4 & \begin{tabular}{|l}
1.8 \\
\end{tabular} & 0 & 0 & 0 & 0 & 0 & 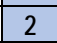 & 7.7 & \begin{tabular}{|l}
1.3 \\
\end{tabular} & 0 & \begin{tabular}{|l|l}
0.4 \\
\end{tabular} & 0 & 0 & 0 & 0 & 0 & 1.9 & 0 & 0 & 2.1 & 0 & & 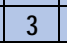 & \\
\hline 14 & 7 & 0 & 0 & 0 & \begin{tabular}{|l|l}
0.5 \\
\end{tabular} & 0 & 0 & 0 & 0 & 0 & 5.3 & 6.6 & \begin{tabular}{|l|l}
4.8 \\
\end{tabular} & 0 & 0 & 0 & 0 & 0 & 0 & 1.3 & \begin{tabular}{|l|}
3.2 \\
\end{tabular} & 0 & 0 & \begin{tabular}{|l|}
2.2 \\
\end{tabular} & 0 & \begin{tabular}{|l|}
2.2 \\
\end{tabular} & \begin{tabular}{|c|}
1.4 \\
\end{tabular} & $\bar{Y}$ \\
\hline 15 & 4 & 0 & 0 & 0 & 0 & 0 & 0 & 0 & 0 & 0 & 1.5 & \begin{tabular}{|l} 
\\
\end{tabular} & 1.4 & 0 & 0 & 0 & 0 & 0 & 0 & 0 & \begin{tabular}{|l}
1.3 \\
\end{tabular} & 0 & 0 & \begin{tabular}{|l|}
0.7 \\
\end{tabular} & 0 & 2.4 & 2.3 & \\
\hline
\end{tabular}

Table 2. Sprint 2 Personality Assessment

\begin{tabular}{|c|c|c|c|c|c|c|c|c|c|c|c|c|c|c|c|c|c|c|c|c|c|c|c|c|c|c|c|c|}
\hline 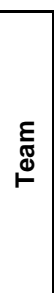 & 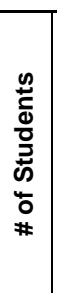 & 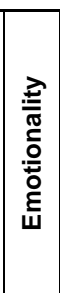 & 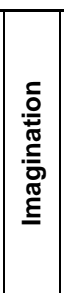 & 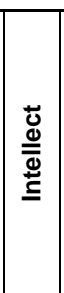 & 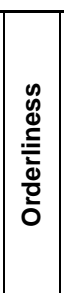 & 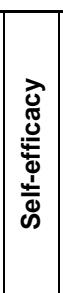 & 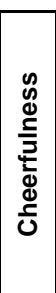 & 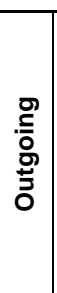 & 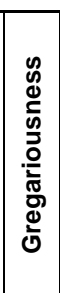 & 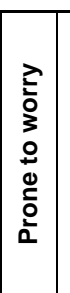 & 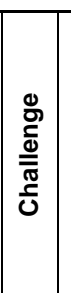 & 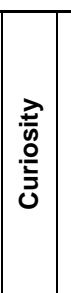 & 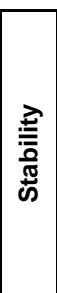 & 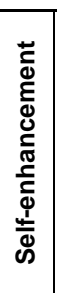 & 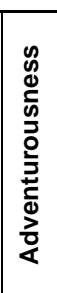 & 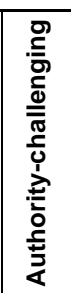 & 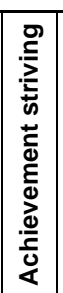 & 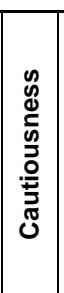 & 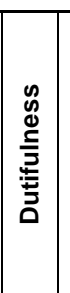 & 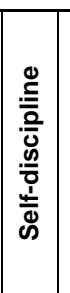 & 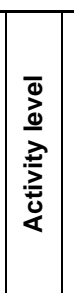 & 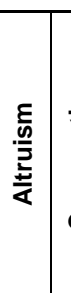 & 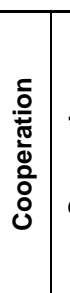 & 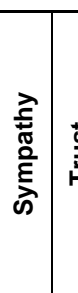 & 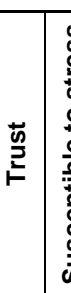 & 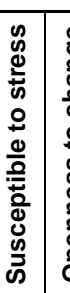 & 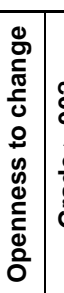 & 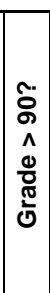 \\
\hline 1 & & & & 3.9 & 0 & 0.8 & 0 & & & 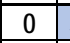 & \begin{tabular}{|l|}
3.6 \\
\end{tabular} & \begin{tabular}{|l|}
3.7 \\
\end{tabular} & I & & 2.5 & 3.52 & 3.5 & \begin{tabular}{|l|}
3.7 \\
\end{tabular} & \begin{tabular}{|l|}
1.5 \\
\end{tabular} & \begin{tabular}{|l|l|}
1.4 \\
\end{tabular} & 3.9 & & \begin{tabular}{l|l}
1.5 & 0 \\
\end{tabular} & \begin{tabular}{l|l}
0.7 & 3 \\
\end{tabular} & 3.6 & & & \\
\hline 2 & 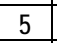 & & & 4 & & 0 & 0 & & & & 0 & 2.8 & 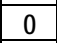 & & 2.1 & \begin{tabular}{|l}
4.52 \\
\end{tabular} & \begin{tabular}{|l|l|}
0.7 \\
\end{tabular} & \begin{tabular}{|l|}
4.7 \\
\end{tabular} & \begin{tabular}{|l|}
2.3 \\
\end{tabular} & & 4.2 & & \begin{tabular}{l|l|}
2.5 \\
\end{tabular} & & 0.7 & & & \\
\hline 3 & 4 & & 0 & & 0 & 0 & & & & 0 & 1.4 & 2.4 & & & & 0.53 & 0 & 2.4 & 0.5 & & 2.2 & & & & & 0.7 & & $\underline{Y}$ \\
\hline 4 & 4 & 0 & 0 & 3. & 0 & 0 & 0 & 0 & 0 & \begin{tabular}{|l|}
0.4 \\
\end{tabular} & \begin{tabular}{|l|}
1.5 \\
\end{tabular} & \begin{tabular}{|l|}
0.7 \\
\end{tabular} & 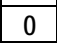 & & \begin{tabular}{|l|l}
1.3 \\
\end{tabular} & \begin{tabular}{|l}
3.78 \\
\end{tabular} & \begin{tabular}{|l|}
1.3 \\
\end{tabular} & 2.7 & \begin{tabular}{|l|l|}
1.5 \\
\end{tabular} & \begin{tabular}{|l|}
0.5 \\
\end{tabular} & 2.5 & & 3.4 & & \begin{tabular}{|l|l}
2.40 \\
\end{tabular} & 0.7 & & $\mathbf{N}$ \\
\hline 5 & 4 & 0 & 0.6 & 3. & 0 & & 0 & & & 0 & 0 & \begin{tabular}{|l|}
3.4 \\
\end{tabular} & & & & 3.82 & \begin{tabular}{|l|}
0.5 \\
\end{tabular} & 3.8 & \begin{tabular}{|l|}
0.7 \\
\end{tabular} & \begin{tabular}{|l|} 
\\
\end{tabular} & 0.5 & & 0.7 & & \begin{tabular}{l|l}
0.6 \\
\end{tabular} & 0.7 & & \\
\hline 6 & 4 & 0 & 0 & 3. & 0 & 0 & 0 & & 0 & 0 & 3.4 & 3.4 & ( & & & 0.7 & \begin{tabular}{|l|}
0.7 \\
\end{tabular} & \begin{tabular}{|l|}
3.7 \\
\end{tabular} & \begin{tabular}{|l|}
2.4 \\
\end{tabular} & \begin{tabular}{|l|}
0.6 \\
\end{tabular} & \begin{tabular}{|l|l}
0.7 \\
\end{tabular} & & 2.5 & & 0.7 & & & \\
\hline 7 & 3 & 0 & 0 & 4. & 0 & 1 & 0 & 0 & C & . & 2.9 & \begin{tabular}{|l|}
4.6 \\
\end{tabular} & & & 1.1 & 2.44 & 2.6 & \begin{tabular}{|l|}
4.8 \\
\end{tabular} & & & & & & \begin{tabular}{|l|l}
0.9 \\
\end{tabular} & 1.1 & & & \\
\hline 8 & 4 & & 2 & & 0 & & & & & & 0 & 2. & 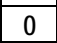 & & \begin{tabular}{|l|l}
0.6 \\
\end{tabular} & 2.62 & 0 & 3.8 & & & 2. & & \begin{tabular}{|l|l|l}
1.5 & \\
\end{tabular} & 0.6 & & 2.3 & & \\
\hline 9 & 4 & 0 & 0 & 3.8 & 0 & 0.5 & 0 & 0 & 0 & 0 & \begin{tabular}{|l|}
1.5 \\
\end{tabular} & 3.5 & 0 & 7 & 2.2 & 3.62 & \begin{tabular}{|l|}
0.6 \\
\end{tabular} & \begin{tabular}{|l|}
3.6 \\
\end{tabular} & \begin{tabular}{|l|}
0.7 \\
\end{tabular} & 0 & 2.6 & & & \begin{tabular}{l|l}
0 \\
\end{tabular} & 3.3 & 0 & 0 & $N$ \\
\hline 10 & 4 & 0 & & & 0 & 0 & 0 & 0 & 0 & 0 & 1.3 & \begin{tabular}{|l|}
3.4 \\
\end{tabular} & 0 & & 1.5 & 1.55 & \begin{tabular}{|l|}
0.6 \\
\end{tabular} & \begin{tabular}{|l|}
3.8 \\
\end{tabular} & \begin{tabular}{|l|l|}
1.4 \\
\end{tabular} & 0.5 & 2.3 & & & \begin{tabular}{l|l}
0.4 \\
\end{tabular} & & & & \\
\hline 11 & 4 & 0 & 0. & 1. & 0 & 0 & 0 & 0 & 0 & 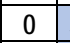 & \begin{tabular}{|l|}
3.6 \\
\end{tabular} & \begin{tabular}{|l|}
3.8 \\
\end{tabular} & 2.4 & & & & & & & & 3.3 & & & 0.7 & & \begin{tabular}{l|l}
3.30 \\
\end{tabular} & $\begin{array}{ll}0.7 \\
\end{array}$ & \\
\hline 12 & 6 & 0 & 0 & 1.3 & & 0 & 0 & 0 & 0 & 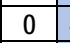 & 4.1 & 5.9 & 0 & & & & & & & & 0.6 & & & & & \begin{tabular}{l|l}
3.2 & 1 \\
\end{tabular} & 1.4 & \\
\hline 13 & 8 & 0 & 4.6 & 2 & & 0 & 0 & 0 & 0 & 7 & & & & & & & 0 & & & & & & & & & 4 & & \\
\hline 1 & & & & \begin{tabular}{|l}
3.1 \\
\end{tabular} & 0 & 0 & 0 & 0 & & & & & 3.1 & & & 0.49 & 1.1 & 1.9 & & 0.7 & 6.3 & & & 1.5 & & \begin{tabular}{|l|l}
1.4 & 1
\end{tabular} & 1.3 & \\
\hline & & & & & & & & & & & & & & & & & & & & & & & & & & & & \\
\hline
\end{tabular}


Table 3. Sprint 3 Personality Assessment

\begin{tabular}{|c|c|c|c|c|c|c|c|c|c|c|c|c|c|c|c|c|c|c|c|c|c|c|c|c|c|c|c|c|}
\hline 焉 & 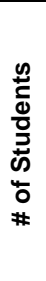 & 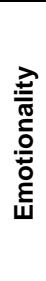 & 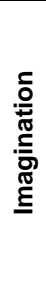 & 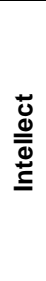 & 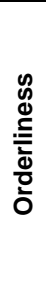 & 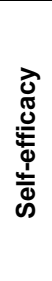 & 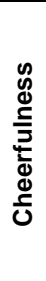 & 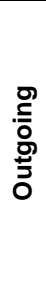 & 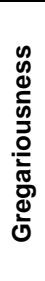 & 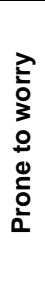 & 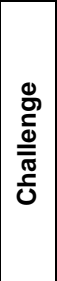 & 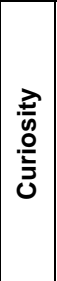 & 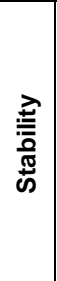 & 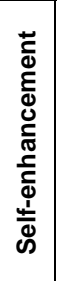 & 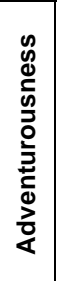 & 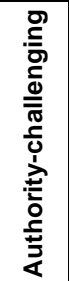 & 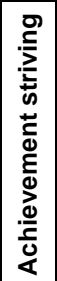 & 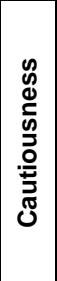 & 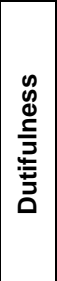 & 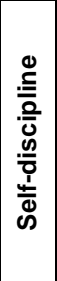 & $\frac{\bar{d}}{\frac{\bar{d}}{2}}$ & 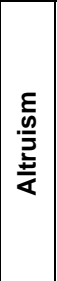 & 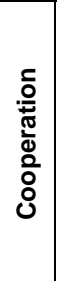 & 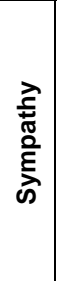 & $\stackrel{\overrightarrow{\underline{n}}}{\stackrel{n}{F}}$ & 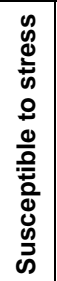 & 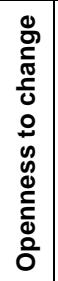 & $\begin{array}{l}\hat{ه} \\
\hat{\Lambda} \\
\hat{0} \\
\frac{\sigma}{0} \\
0\end{array}$ \\
\hline 1 & 4 & c & 0 & & c & & c & & & 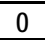 & 3.7 & 3.4 & 0 & 0.5 & \begin{tabular}{|l|}
1.6 \\
\end{tabular} & 2.24 & 3.4 & \begin{tabular}{|l|}
3.6 \\
\end{tabular} & \begin{tabular}{|l|}
1.5 \\
\end{tabular} & \begin{tabular}{|l|}
2.2 \\
\end{tabular} & 3.8 & & 2.3 & 0 & 3.6 & 0 & 0 & $\mathrm{Y}$ \\
\hline 2 & 5 & 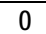 & 0 & & c & & & & & & 1.4 & 2.3 & 0 & & 0.6 & 4.18 & 0 & 4.7 & \begin{tabular}{|l|}
3.2 \\
\end{tabular} & & 2.3 & & 3.3 & & 1.3 & 0.7 & 0.4 & $\mathrm{~N}$ \\
\hline 3 & 4 & 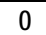 & 0 & 2.3 & 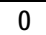 & 0.5 & 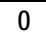 & & & 0 & 1.6 & 2.3 & 0 & & \begin{tabular}{|l|}
0.6 \\
\end{tabular} & 1.23 & 0 & 1.5 & 0 & & 2.4 & & 0.5 & & 1.3 & \begin{tabular}{|l|}
0.7 \\
\end{tabular} & 1.9 & $\mathrm{~N}$ \\
\hline 4 & 4 & ( & 0 & 2.5 & c & 0 & 0 & 0 & & 0 & 2.4 & 2.2 & 0 & 0 & 0 & 2.35 & 1.4 & 3.8 & 2.3 & 0 & 2.4 & & 2.4 & & 1.4 & 0 & 0 & $\mathrm{~N}$ \\
\hline 5 & 4 & 0 & 0 & 3.6 & 0 & 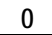 & c & 0 & & c & 0 & 0.6 & 0 & 0 & 0 & 1.56 & 0.4 & 3.7 & 0.7 & 0 & 0 & & 2.4 & 0 & \begin{tabular}{|l|}
0.5 \\
\end{tabular} & 0.6 & 0 & $\mathrm{~N}$ \\
\hline 6 & 4 & 0 & 0 & 1.6 & 0 & ( & 7 & & ( & 0 & 2.3 & 1.6 & 0 & 0 & 0 & 0.55 & 0.6 & 2.2 & 2.3 & 0 & 0 & & 2 & 0.6 & 0 & 1.3 & 0.5 & $N$ \\
\hline 7 & 3 & 0 & 0 & 2.6 & 0 & 2.6 & c & 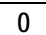 & & 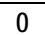 & 2.8 & 2.6 & 0 & 0 & \begin{tabular}{|l|}
0.8 \\
\end{tabular} & 0 & 2.8 & 2.9 & 2.7 & 2.6 & 2.9 & & 0 & & 1.6 & 0 & 0 & $Y$ \\
\hline 8 & 4 & 0 & 0 & 2.5 & 0 & 0.7 & 0 & 0.4 & 0 & 0 & 2.2 & 3.5 & 0.4 & \begin{tabular}{|l|}
0.4 \\
\end{tabular} & \begin{tabular}{|l|}
0.6 \\
\end{tabular} & 0.63 & \begin{tabular}{|l|} 
\\
\end{tabular} .4 & \begin{tabular}{|l|} 
\\
\end{tabular} & \begin{tabular}{|l|}
1.5 \\
\end{tabular} & 0.7 & 2.6 & & 2.4 & 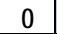 & 2.4 & 1.4 & 0.6 & $Y$ \\
\hline 9 & 4 & 0 & 0 & 2. & 0 & 1.5 & 0 & 0 & 0 & 0 & 2.5 & 2.4 & 0 & \begin{tabular}{|l|}
1.4 \\
\end{tabular} & \begin{tabular}{|l|}
1.2 \\
\end{tabular} & \begin{tabular}{|l|}
3.4 \\
\end{tabular} & 2.4 & 2.4 & 0 & 0.6 & 3.8 & & 0.6 & & 3.6 & 0 & 0.6 & $Y$ \\
\hline 10 & 4 & 0 & 0 & 3.8 & 0 & 0 & 0 & & 0 & 0 & 0.6 & 2.3 & 0 & 0 & 0 & 2.29 & 0.4 & 3.7 & \begin{tabular}{|l|}
1.4 \\
\end{tabular} & 0 & 0.6 & 0 & 0 & 0 & 0 & 0.6 & 0 & $Y$ \\
\hline 11 & 4 & 0 & 0.6 & 0 & 0 & 0 & c & 0 & 0 & 0 & 3.6 & 3.8 & 2.3 & 0 & 0 & 0 & 0 & 0 & 0 & 0 & 1.5 & & 0 & 0 & 0 & 3.4 & 1.4 & $Y$ \\
\hline 12 & 6 & 0 & 0 & 0 & 0 & 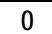 & 0 & c & 0 & 0 & 3.2 & 5.8 & \begin{tabular}{|l|}
0.7 \\
\end{tabular} & 1.3 & 0 & 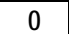 & 0 & 0.5 & 0 & 0 & 0.6 & & & 0 & 0 & 5.1 & 0 & $\bar{Y}$ \\
\hline 13 & 8 & 0 & 1.4 & 0 & 0 & 3. & 0 & 0 & 0 & 2.1 & 6 & 7.7 & 2.2 & 0.6 & 0 & 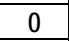 & 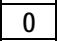 & & 0 & 0 & 3. & & & 0 & & 7.2 & 4.8 & $\mathrm{~N}$ \\
\hline 14 & 7 & 0 & 0 & 2 & 0.5 & 0.6 & 0 & 0 & 0 & 0 & 5.3 & 6.7 & & 2 & & 0 & & & \begin{tabular}{|l|}
0.5 \\
\end{tabular} & 0.7 & 5.9 & & & 0.7 & & 2.2 & 3 & $Y$ \\
\hline 15 & 4 & 0 & 0 & 0 & 0 & 0 & 0 & 0 & 0 & 0 & 1.5 & 3.6 & 2.3 & 0 & 0 & 0 & 0 & 0.7 & 0 & 0.7 & 2.3 & 0 & 0 & 0 & 0 & 0.7 & 0 & $\mathbf{N}$ \\
\hline
\end{tabular}

Interestingly, teams with low achievement striving traits also performed better. We note two potential reasons why this result emerged. First, it is possible that those teams that had high achievement striving members attempted to do too much and failed to deliver a good project. It could also be that this trait has a relation to the intellect trait, as team members may not want to strive for additional achievements because they are less open to the new ideas required.

It is also odd that teams with a low Dutifulness trait were more likely to get a higher grade. This could be related to the Susceptible to Stress trait, as when students are stressed they are more likely to slack on some of their duties. It is possible that the teams that were highly stressed would work in bursts, failing to get their portion of the projects done on time or early, but succeeding overall. This scenario could lead to a lower dutifulness value.

Table 2 shows the results for sprint 2. For this sprint, where the students are more familiar with the way the class is run and the grades themselves, more teams had students with grades above 90 . There is no real consistency between the traits and high grade for sprint 2, other than all teams having activity level and curiosity traits, and most teams having Intellect and Cautiousness traits. It can be said that especially for sprint 2, where the teams are focused mostly on development, these traits are important. Those with Intellect and Curiosity traits are more likely to succeed at tasks which require them to learn new things, and a high Activity Level will lead to more work being completed. We also see Openness to Change as an important factor for grade. Sympathy is also important for grade, as sympathetic team members are more likely to understand if a team member misses a deadline or has a problem with the project. Especially with sprint 2, which includes midterms and project deadlines for other courses, sympathy is a vital trait for team grades.

Sprint 3 (Table 3) has only two traits present for over half the teams that had high grade, Self-Efficacy and Self-Discipline. These traits are both beneficial for sprint 3, as classes wind down, because selfdisciplined team members are more likely to finish the project rather than slack off at the end of the year and self-effacing team members are likely to believe they can finish the project and push towards that goal. Two traits appear in 4 of the 8 teams that had high grades, Stability and Openness to Change. Again, these are reasonable for teams at the end of the year, as stable team members are likely to be able to complete the assignment and those willing to make changes at the end to improve the product are likely to successfully complete the sprint. 
Table 4. Correlation Results across Sprints

\begin{tabular}{|c|c|c|c|c|c|c|c|c|c|c|c|c|c|c|c|c|c|c|c|c|c|c|c|c|c|c|}
\hline & 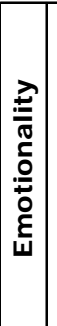 & 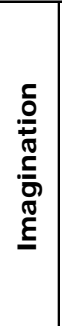 & 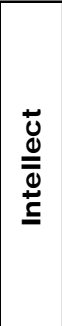 & 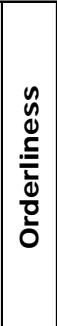 & 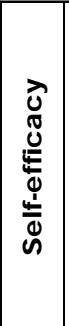 & 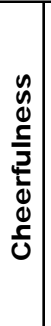 & 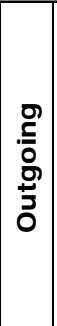 & 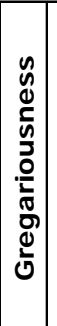 & $\begin{array}{l}2 \\
0 \\
3 \\
0 \\
0 \\
0 \\
0 \\
0\end{array}$ & 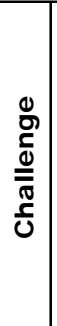 & 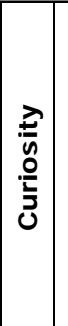 & $\frac{2}{\frac{D}{2}}$ & 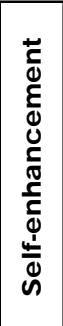 & 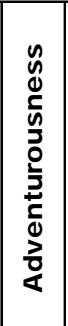 & 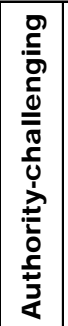 & 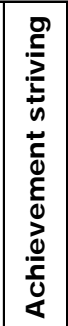 & 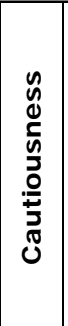 & 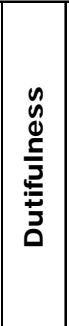 & 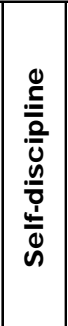 & $\frac{\substack{\bar{d} \\
\frac{d}{2}}}{\frac{2}{2}}$ & $\mid \begin{array}{l}\frac{E}{n} \\
\frac{n}{z} \\
\frac{\mathbf{n}}{\mathbf{\alpha}} \\
\end{array}$ & 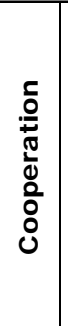 & 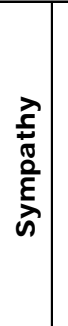 & $\begin{array}{l}\stackrel{n}{n} \\
\stackrel{2}{r}\end{array}$ & 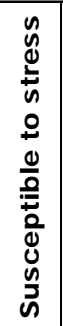 & 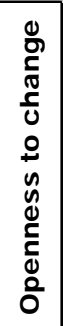 \\
\hline Sprint 1 & & 0.39 & -0.39 & 0.56 & -0.50 & & & & -0.19 & 0.10 & 0.60 & 0.59 & -0.44 & -0.31 & -0.25 & \begin{tabular}{|l|}
-0.54 \\
\end{tabular} & -0.25 & -0.09 & -0.13 & -0.41 & & -0.06 & 0.47 & -0.36 & 0.59 & 0.39 \\
\hline Sprint 2 & & 0.07 & \begin{tabular}{|l|l|} 
\\
\end{tabular} & 0.16 & \begin{tabular}{|l|}
0.14 \\
\end{tabular} & & & & -0.08 & 0.44 & \begin{tabular}{|l|}
0.39 \\
\end{tabular} & 0.25 & $\mid-0.80$ & 0.06 & 0.01 & 0.12 & \begin{tabular}{|l|}
0.16 \\
\end{tabular} & \begin{tabular}{|l|}
0.19 \\
\end{tabular} & \begin{tabular}{|l|}
-0.47 \\
\end{tabular} & \begin{tabular}{|l|l|}
0.18 \\
\end{tabular} & & 0.21 & |0.37- & -0.17 & 0.20 & 0.23 \\
\hline Sprint 3 & & -0.20 & \begin{tabular}{|l|}
0.21 \\
\end{tabular} & 0.06 & \begin{tabular}{|l|}
0.26 \\
\end{tabular} & & 0.06 & & -0.23 & 0.11 & 0.03 & \begin{tabular}{|l|}
-0.08 \\
\end{tabular} & \begin{tabular}{|l|}
0.29 \\
\end{tabular} & \begin{tabular}{|l|}
0.51 \\
\end{tabular} & \begin{tabular}{|l|}
0.09 \\
\end{tabular} & \begin{tabular}{|l|}
0.53 \\
\end{tabular} & \begin{tabular}{|l|}
0.11 \\
\end{tabular} & \begin{tabular}{|l|}
0.13 \\
\end{tabular} & \begin{tabular}{|l|}
0.55 \\
\end{tabular} & $\begin{array}{ll}0.15 \\
\end{array}$ & & -0.27 & 0.04 & 0.36 & -0.16 & \begin{tabular}{|l|}
-0.23 \\
\end{tabular} \\
\hline
\end{tabular}

To answer hypothesis 1 , we examine the weighted tables. If the weight is above 1.5, we confirm that the collaborative personality trait strongly exists in the team. Thus, hypothesis 1 is supported. One observation is that Emotionality, Cheerfulness, Gregariousness, and Altruism never have a single team member with the trait.

To answer hypothesis 2, we ran a correlation between the weighted averages and grade. The results appear in Table 4. Our critical values are as follows:

- $|\mathrm{r}|>0.402$ corresponds to a very strong correlation with $\mathrm{p}=0.01$ (positive shown as light green, negative shown as light red)

- $|r|>0.312$ represents strong correlation with $p$ $=0.05$ (positive shown as dark green, negative shown as dark red)

- $|\mathrm{r}|>0.263$ represents significant correlation with $\mathrm{p}=0.10$ (positive shown as yellow, negative shown as orange)

For Sprint 1, 7 traits were positively correlated with grade, with Imagination and Openness to Change being strongly correlated and Orderliness, Curiosity, Stability, Sympathy, and Susceptible to Stress all being very strongly correlated. This result aligns with our previous discussion based only on the weighted average tables. The negative grade correlations from sprint 1, which are Adventurousness, Intellect, Trust, Self-Efficacy, Selfenhancement, Achievement Striving, and Activity Level, also follow from our initial observations. It is reasonable to look at the results from sprint 1 and say that the personality traits have a significant effect on grade, making it important for instructors or managers to encourage traits like Orderliness, Curiosity, Stability, Sympathy, and Imagination but at the same time notice the presence of Achievement Striving, Self-enhancement, and Self-efficacy traits of the team members. Though these are negatively correlated, they should not necessarily be discouraged in team members, as they have been identified as useful in team performance. For example, in sprint 1 , the instructor can make students aware that team achievement and team task deliverables are more important than just personal achievement. When students strive for team achievement they can apply their self-efficacy skill positively to make it work well for the team success.

For sprint 2, there are significantly fewer traits that correlate with grade. However, there is a very strong negative correlation with self-enhancement and self-discipline. One would expect that selfdiscipline is a trait that always results in higher grade. Sometimes working more individually does not produce the desired result if it does not align with team activities. Thus, it is possible that students may be concerned with their own self-enhancement rather than team success. An instructor can take steps to encourage students to be aware that the team success is also their personal success. As we discussed with our first tables, curiosity and intellect both correlate with grade and are both needed for sprint 2 success. However, challenge and sympathy also both correlate with grade, suggesting that having sympathy for the stress and challenges of the middle of the project are important for team success, as is an urge to succeed and be challenged.

Sprint 3 has an unexpected flip for self-discipline, going from negatively to positively correlated. This makes sense for sprint 3 in the educational context, as it is at the end of the semester and those students who are self-disciplined are more likely to complete the project successfully. Unlike our initial observations, self-efficacy does not correlate with grade. However, adventurousness, achievement striving, trust, and self-enhancement all do correlate directly with grade. These traits are definitely important in sprint 3 , with the project winding down and solutions to problems 
needing to be found and implemented. Shockingly, cooperation is negatively correlated with grade, suggesting that, at the end of a project, it is more important to have every team member do their own work rather than work together to finish their project. Though cooperation correlates negatively, the instructor may make students aware that cooperation is important at specific points of sprint 3 rather than encouraging cooperation at unnecessary parts of the sprint, such as when a team member is performing a highly focused task.

Based on these results, hypothesis 2 is partially supported. Many of the collaboration traits do correlate, at least once, with grade. However, not every team with a weight greater than 1.5 correlate with grade, with prone to worry, authoritychallenging, cautiousness, outgoing, and dutifulness all having at least one user with a personality strength value over 0.75 and no correlation to grade.

\section{Conclusion}

Part of educating the next generation of software engineers includes training them to collaborate in ways that lead to a positive product outcome. In this paper, we classified 26 personality traits from the IBM Watson Insight service for a software engineering undergraduate capstone course and then examined team performance based on the traits that appeared in the team. We used Slack.com posts from 69 students across 15 teams over 3 sprints to study. We found interesting patterns across different sprints for both commonly-found and rare traits. These results can be used to identify personality types when creating teams to maximize the desired performance metric, in this case grade. They can also be used to promote and reward collaborative activities.

We acknowledge that our work has some limitations. First, the data for the study is limited to 69 students over three semesters and 15 teams. We must consider that there are other factors which may affect team performance. To collect more data, we will continue this study over the coming year. It is also possible that the different tasks associated with and the differing length of each sprint could cause variance in the data that is not accounted for. For example, sprint 1 gets the students full attention, as there are few projects occurring in other courses, while sprints 2 and 3 compete with midterms, projects, and finals for other courses. Our methodology also prevents the analysis of the contribution of high performing and low performing team members by focusing only on the final deliverable. In the future, we will attempt to separate the amount of work done by individual team members for a more accurate understanding of individual team members' contributions, allowing analysis of high-performing members that may carry the team. Finally, it is possible that the analysis performed by Watson is less accurate for students that rarely use slack. We have attempted to account for this by only using the metrics Watson is most confident on, but it is possible some very low posting students may not be captured accurately.

Others have looked at different methods of team creation, including random creation [2], separating students into groups and selecting one member from each group [21], and allowing self-created teams [29]. Each of these resulted in teams that underperformed, either because of single student was doing all the work, personality conflicts, or the demoralizing of students due to not being picked. It is possible that a larger team size may make these conflicts less apparent, as team members with nonconflicting traits can help smooth over conflicting traits in other team members. We plan to examine the effect of team size on grade in the future. But team creation can still lead to issues given the interplay of both personality and skillset among team members. By understanding the roles that various collaborative personality traits play in the software development process, we can train students to discover their own and their team members' collaborative personality traits. In addition, we can create mechanisms that incorporate and reward different collaborative behaviors beyond asynchronous interaction, to encourage adoption of these traits.

\section{References}

[1] V. Balijepally, R. Mahapatra, S.P. Nerur, “Assessing personality profiles of software developers in agile development teams”, Commun. ACM, 2009, 18:4(5475).

[2] M.C. Bastarrica, D. Perovich, and M.M. Samary, "What can students get from a software engineering capstone course?”, IEEE/ACM 39th International Conference on Software Engineering: Software Engineering Education and Training Track, 2017.

[3] R. Baumgart, M. Hummel, and R. Holten, "Personality traits of scrum roles in agile software development teams - A qualitative analysis", European Conference on Information Systems, 2015.

[4] G. Beranek, W. Zuser, and T. Grechenig, "Functional group roles in software engineering teams", In Proceedings of the Workshop on Human and Social Factors of Software Engineering, 2005.

[5] F. Calefato, F. Lanubile, and N. Novielli, "A preliminary analysis on the effects of propensity to trust in distributed software development”, IEEE 12th 
International Conference on Global Software Engineering, 2017.

[6] L. Cao, E.H. Park, S.P. Nerur, "Understanding goaldirected emotions in agile software development teams”, Twenty-third Americas Conference on Information Systems, 2017.

[7] L.F. Capretz and F. Ahmed, "Making sense of software development and personality types", IT Professional, 2010, 12:1(6-13).

[8] T. Chow and D. Cao, "A survey study of critical success factors in agile software projects", J. Syst. Softw., 2008, 81:6(961-971).

[9] P. Costa and R. McCrae, "Revised NEO personality inventory (NEO-PI-R) and NEO five-factor inventory (NEO-FFI) manual”, Odessa, FL: Psychological Assessment Resources, 1992.

[10] C. Dunlap, "Problem-based learning and self-efficacy: How a capstone course prepares students for a profession”, Educational Technology Research and Development, 2005, 53:1(65-83).

[11] D. Graziotin, F. Fagerholm, X. Wang, and P. Abrahamsson, "Consequences of unhappiness while developing software”, IEEE/ACM 2nd International Workshop on Emotion Awareness in Software Engineering, 2017.

[12] E. Guzman and B. Bruegge, "Towards emotional awareness in software development teams", Proceedings of the 9th Joint Meeting on Foundations of Software Engineering, 2013.

[13] J.R. Hackman and R. Wageman, "When and how team leaders matter", Research in Organizational Behavior, 2004, vol. 26, pp. 37-74.

[14] O.P. John and S. Srivastava, "The big five trait taxonomy: History, measurement and theoretical perspectives”, In Handbook of Personality: Theory and Research: Second Edition, The Guilford Press, New York, 1999, pp. 102-138.

[15] T.A. Judge, A. Erez, and J.E. Bono, "The power of being positive: The relation between positive selfconcept and job performance”, Human Performance, 1998, 11:2-3(167-187).

[16] F. Lanubile, "Collaboration in distributed software development", Lecture Notes in Computer Science, 2009, pp. 174-193.

[17] L. Layman, T. Cornwell, and L. Williams, "Personality types, learning styles, and an agile approach to software engineering education", Proceedings of the 37th SIGCSE technical symposium on Computer science education, 2006.
[18] P.L. Li, A.J. Ko, and J. Zhu, "What makes a great software engineer?”, IEEE/ACM 37th IEEE International Conference on Software Engineering, 2015.

[19] Y. Lindsjørn, D.I.K. Sjøberg, T. Dingsøyr, G.R. Bergersen, and T. Dybå, "Teamwork quality and project success in software development: A survey of agile development teams”, J. Syst. Softw., 2016, vol. 122, pp. 274-286.

[20] P. McCuller, "How to recruit and hire great software engineers: Building a crack development team", (1st ed.). Apress, Berkely, CA, USA, 2012.

[21] M. Missiroli, D. Russo, and P. Ciancarini, "Learning agile software development in high school", Proceedings of the 38th International Conference on Software Engineering Companion, 2016.

[22] A. Murgia, M. Ortu, P. Tourani, B. Adams, and S. Demeyer, "An exploratory qualitative and quantitative analysis of emotions in issue report comments of open source systems”, Empirical Software Engineering, 2017, 23:1(521-564)

[23] W. Norman, “Toward an adequate taxonomy of personality attributes: Replicated factor structure in peer nomination personality ratings", Journal of Abnormal and Social Psychology, 1963, 66:6(574583).

[24] A. Pentland, "The new science of building great teams”, Harvard Business Review, 2012, 90:4(60-70).

[25] B. Ramesh, L. Cao, K. Mohan, and P. Xu, "Can distributed software development be agile?”, Commun. ACM, 2006, 49:10(41- 46).

[26] J. Rasmusson, "The agile samurai: How agile masters deliver great software", (1st ed.). Pragmatic Bookshelf, 2010.

[27] C.B. Seaman, "Qualitative methods in empirical studies of software engineering”, IEEE Transactions on Software Engineering, 1999, 25:4(557-572).

[28] K.T. Stevens, “The effects of roles and personality characteristics on software development team effectiveness", Ph.D. Dissertation, Virginia Polytechnic Institute and State University, 1998.

[29] T.M. Vitolo, K.E. Hersch, and B.J. Brinkman, "Making the connection: Successful cross campus collaboration among students”, IEEE Frontiers in Education Conference, 2016.

[30] J. Whitehead, I. Mistrík, J. Grundy, and A.V. Hoek, "Collaborative software engineering: Concepts and techniques", Collaborative Software Engineering, Springer, 2010, pp. 1 - 30. 